\title{
Intergenerational Transmissions and Race Inequalities: Why the Subjective and Relational Matter
}

\author{
Joy Moncrieffe
}

\begin{abstract}
In this article, I highlight some of the ways in which racial perceptions and inequalities can become ingrained; how these inequalities are transmitted across generations; the factors and conditions that can disrupt intergenerational transmissions (IGTs) of race and class inequalities; and the importance and urgency of stemming such IGTs from childhood. The article stresses the importance of analysing and responding to how 'agency' is being cultivated among different categories of children - because of the structural conditions, the quality of policy interventions and the actions and inactions of people within and external to their contexts.
\end{abstract}

\section{Background}

In 'Thinking Race, Thinking Development', Sarah White (2002) argued that despite the centrality of race to development, the subject has remained effectively 'non-framed', which means that it has been 'omitted from policy and programme agendas', remaining 'unseen and unheard for a variety of reasons' (Moncrieffe 2007a: 3). White explored aspects of the power relations that have perpetuated this 'determining silence', as well as some of the covert and overt ways in which the racial power structures and relations that were cultivated throughout colonialism have continued to permeate development thought and practice. 'The language of development', she observes, 'is rooted in the colonial encounter' (2002: 411) and colonialism has left a massive imprint on race relations and perceptions. White agrees with Mudimbe (1988) that in order to understand colonialism's power to influence and even 'invent' race relations, it is necessary to go beyond the conceptualisation of power as domination, for while it is true that colonialism involved 'the domination of space' and overt, agonising exploitation, it also entailed more subtle and, arguably, effective techniques: transforming consciousness and integrating the histories and economies of the colonised countries within a Western 'master narrative' (White 2002: 411). Therefore, White maintains that colonialism was not simply 'a military, political and economic enterprise'; it was also 'a discursive regime of power/knowledge' (Foucault 1972, 1980).

White is clear that some of the adverse, colonial and racial meanings still permeate development agencies and are demonstrated in more and less explicit ways, such as in bar talk among expatriates, employment procedures, education programmes and relationships of aid. Her article is, perhaps, better known for its exposure of these well-known secrets than for its reference to the unexpected 'meanings' of race among those whom she depicts as the objects of racial labelling.

However, the latter is an especially important subject, for development processes are not merely affected by how those who are regarded as more powerful manage to 'categorise' but also by how those regarded as adversely categorised come to categorise themselves, particularly how they view themselves in relation to 'others'. Selfcategorisation reflects internalised power: resistance, submission and different forms of agency come from within individuals. Structures and processes of domination are always at risk where people purpose within themselves to 
challenge and disrupt them. Conversely, all sorts of inequalities can remain intact and become chronic where people hold unfavourable and patently disempowering perceptions of themselves.

Why are these subjective and relational dimensions of development issues avoided? There is a plausible argument that dominant economic models of development are instrumental in ensuring that issues such as race are overlooked. According to some economic perspectives, racial and other such constructions are, primarily, ways of regulating relationships in resource allocation. Consequently, if growth and redistribution were improved, social - including racial - divisions would subside. Using this argument, the post-revolution Cuban government invested in structural reforms and prohibited discussions of race, believing that racial divisions persisted in contexts of low levels of material welfare (De la Fuente 2001; McKnight 1996: 106). However, there is debate about the success of these strategies. In many countries, structural reforms have had advantages but have not eliminated racial discrimination. This is because ideas on race can become deeply embedded and can persist, stubbornly, across generations. For example,

In Bermuda, where racial segregation was enforced up to 1959, the Human Rights Commission recorded high levels of racial complaints decades later (Dill 2001). In Barbados, where discussions of racial tensions remained muted for some time, the 2001 National Committee on Reconciliation reported that all communities feel aggrieved, despite their economic advancement: whites feel that they are constantly attacked for their ancestors' roles in the country's history; blacks complain that they are still denied equal access to employment; Indians maintain that their culture is not recognized and accommodated (Babb 2002). (Moncrieffe 2004: 8)

Therefore, where they assume that individuals, inevitably, prioritise their individual economic self-interests and that the solutions to even some of the most deep-seated social and cultural issues are, nevertheless and always, exclusively rooted in economics, development approaches are likely to fail to tackle some core development problems at their roots. Arguably, social and cultural approaches to development could also do more to properly recognise and deal with issues of race and, surprisingly, in recent periods, there is also a palpable silence on issues of class. This, in part, explains why some debates on gender equality tend to assume that men, women and children experience inequalities in the same 'gendered' ways; this is a narrow analytical approach, which overlooks the differences that occur because of 'intersectionalities', such as of race and class. ${ }^{1}$

\subsection{Article overview}

In this article, I argue that it is important to probe 'the regimes of power/knowledge' that produce what White (2002) describes as a 'determining silence' on matters such as race and that encourage 'politically correct development' strategies, which blind development actors to how some of the policies they implement or fail to implement can allow racial inequalities to be transferred across generations. I focus, particularly, on some of the ways in which adverse racial perceptions and inequalities can become ingrained; how these inequalities are transmitted across generations; the factors and conditions that can disrupt intergenerational transmissions (IGTs) of racial inequalities; and the importance and urgency of stemming such IGTs from childhood.

The empirical data that is presented in the first part of the article is derived from a series of interviews and focus group discussions that were conducted in four remote villages in Uganda in 2007. The study was designed to assess the effectiveness of one agency's sponsorship programmes. Therefore, the interviews and focus group discussions included views from parents of sponsored and non-sponsored children, community leaders, community volunteers and children aged 6-18 - both sponsored and non-sponsored. As the study is limited to four rural villages, there is no assertion that findings are representative of views throughout all of Uganda. The second set of data comes from interviews, which were conducted in Jamaica and Haiti during 2005-7. The interviews in Jamaica included 300 children across social classes and were part of a larger research agenda on childhood, citizenships and violence. The interviews in Haiti focused especially on 'street children' and 'restavecs' but also included children from one elite, predominantly white, school.

The stories reveal how patterns of meanings (Geertz 1973; see also UNFPA 2008) are honed 
within particular physical, psychological, social and economic boundaries, and the varied consequences of these meanings for the children who are being shaped in these contexts. Young children are vulnerable, particularly to the lessons that are learnt during the primary and secondary phases of their socialisation. During these phases, values, norms, customs, messages about their place in the world and the appropriate ways of relating to different types of people in the world can become imprinted in their psyches and may have lasting influence. However, children are also resilient and do exercise agency, to varied ends and with varied consequences. The article stresses the importance of analysing and responding to how 'agency' is being cultivated among different categories of children - because of the structural conditions, the quality of policy interventions and the actions and inactions of people within and external to their contexts.

Section 2 synthesises some key thoughts on how the patterns of meanings within different contexts influence the cultivation of agency among children. Section 3 uses case examples to analyse some of the factors that produce cultures of racial inequality and the conditions under which these may be sustained and transmitted across generations. Section 4 focuses on the quality of policy interventions and demonstrates how these can sustain and/or disrupt IGTs of race and class inequalities.

\section{Patterns of meanings: understanding the principles}

There is too little attention in development to how the lessons that children learn and their experiences throughout childhood influence their life chances. This oversight has much to do with how children are themselves framed in development policy and advocacy - where they have comparatively minimal voice and visibility but it also has to do with what counts as development knowledge and how, among many policymakers and practitioners, cultural approaches to development and disciplines such as psychology and anthropology still have little influence on how issues are understood, problematised, prioritised and responded to.

It is fairly well accepted within anthropology, sociology and psychology that the patterns of meanings that people inherit and share influence how they perform as development actors. Through processes of socialisation, people acquire common understandings of what is significant and not. They depict these understandings through their use of symbols, the types of relationship they cultivate and through norms, values and customs. Across and among all peoples, these processes of socialisation and acculturation involve relations of power coercive and non-coercive; visible and hidden; agreed and imposed. As social actors, people maintain 'norms of mutual accountability and susceptibility' (Barnes 2000) and can, therefore, accept the norms, values and customs that surround them, even where these appear to cause personal disadvantage; people who appear to lose from 'the way things are' may, yet, vigorously defend the status quo. However, on the other hand, the meanings that appear dominant within societies are often those held by people who maintain the most power - these people can be located within or external to local cultures and who act, whether by demand, on command or on personal initiative, as the cultural interpreters.

Bourdieu (1980) explains that through such processes, 'society becomes deposited in persons in the form of lasting dispositions or trained capacities and structured propensities to think, feel and act in determinate ways'. This 'habitus', he notes, is socially acquired and varies across contexts and across distributions of power. Therefore, Bourdieu uses the concept of 'habitus' to describe the route through which internalised power becomes culture. As Bourdieu explains, habitus is not fixed, though it has lasting influence; habitus - and cultures - can be changed when there are 'effective external counteracting influences' (see Wacquant 2005). However, while Bourdieu focuses on the importance of external stimuli for change, it is known that internal changes may occur without this outside influence. This is because cultures are not inflexible; there are contestations within them, for although cultures 'affect how people line up and how they act on a wide range of matters' (Ross 1997: 42), they do not cause uniform thoughts or behaviours. 'Individuals who live within the same cultural setting can hold antagonistic convictions, based on different values' (Chabal and Daloz 1988: 88). In the same way, people within the most oppressive circumstances can, nevertheless, find ways of 
resisting their domination; as Hayward (2000) describes it, they are capable of acting even in the face of boundaries to action (see also Scott 1985).

Greig and Tadros (in this IDS Bulletin) both make the important point that children and young people are not simply empty vessels awaiting socialisation; rather, they also actively construct their social worlds. However, there is something distinct about children's earliest experiences. As Jenkins (2004: 19) explains, selfhood is not fixed; it is best conceptualised as 'an ongoing and, in practice, simultaneous synthesis of (internal) selfdefinition and the (external) definitions of oneself offered by others (ibid.). ${ }^{3}$ As young humans are dependent, the external moment of that dialectic may be more significant during childhood:

Very young humans are dependent: there is much that they must discover about the world and their place in it. All things being equal, they are hard-wired to be voracious learners, and they must learn who's who and what's what. Identities established during infancy and childhood may be less flexible than identities that are acquired subsequently. On the face of things, identification is neither remorselessly permanent nor frivolously malleable. The most adamantine identity has some leeway in it, if only as a sense of possibility. But the more unilateral the internal-external traffic, the less negotiable the resultant identity is likely to be, the smaller the room for manoeuvre. Identifications entered into early in life are experienced as more authoritative than those acquired subsequently: at most, infants and very young children can only muster weak responses of internal self-definition to modify or reject them. Assumed during the most foundational learning period, they become part of the individual's axiomatic furniture: the way things are. (Jenkins 2004: 19)

Therefore, the patterns of meaning that children learn throughout infancy and childhood can have long-term influence and are more easily disrupted when they are provided with sound reasons and means to challenge and overturn them; forms of agency are cultivated, as children learn from and negotiate their contexts.

\section{Exploring patterns of meanings}

We were in a remote rural village in Uganda, a team of researchers who had been commissioned to evaluate one agency's child sponsorship programmes. The discussion had taken a surprising turn. I asked one group of parents about their perceptions of the child sponsors and this triggered a discussion of race. We decided to continue the inquiry in the other villages that were selected for study. The findings were fairly consistent: The majority of respondents, children to adults, identified the mzungu (white person) as the sponsor because he/she was racially superior, either for material reasons or his/her inherent goodness or morality; there were only few dissenting voices. I was disturbed by the pervasiveness of these responses. Growing up as a black child in post-colonial Jamaica, I was aware of this type of racial self-deprecation. However, Jamaica has undergone some important social changes: the Black Power movement - influenced by key personalities such as Marcus Garvey and Walter Rodney - has been particularly influential in presenting counterideologies. I was keen to explore why these 'selfrestricting' ways of thinking were so prevalent in these villages.

Question: Why do you think that Mzungu is the sponsor?

Man: Because white people are kinder than black people.

Woman: White people are born blessed.

Man: White people are better than black people. Why?

White people love black children, especially orphans.

[Immediately, some people complained ... not only orphans, they love other people as well.] Man: To me, even Africans are kind. That's why we have received you Joy. But somehow, white people out of whatever they get, put something aside to help those in need. Some Africans do the same but some don't. Woman: This does not mean that they are a higher race.

Man: White people have knowledge and economic power over us.

Question: Are you suggesting that one race is superior to the other?

Here, there was some disagreement over whether whites were superior to blacks. An albinistic man stands - all laugh disparagingly. ${ }^{4}$ The man perseveres: Whites and blacks are not the same. White people's economic resources are different from ours. Man: We are not the same. Whites are in developed countries; we blacks are developing. That's why they have come to assist us. 
Man: We are not the same. They colonised and ruled us and left us behind.

Woman: We are the same. These white people come and do research; this means there is something we know that they don't.

Woman: There are rich whites and rich blacks; we are the same.

Man: White people come in big vehicles; blacks are on foot. Even poor whites are not the same as poor blacks. Man: [This sponsorship organisation's] programmes sanction whites. It is white people who are helping them.

Question: What do your children think about this issue?

Man: Our children also think white people are better than them. The way parents think is the way children think.

As the parents predicted, interviews among the children revealed similar patterns. For example, in one parish, children reasoned that no black person could become a doctor; while black people are able to carve wood, white people can work with iron, which requires much more skill. The vast majority of teachers in that parish offered similar opinions. They had no doubt about white superiority, stating clearly that while white people have abundant resources, black people could not even feed their children.

The conversations above underscore that there are disparities of views within a common culture. They display the unpredictability of cultures/patterns of meanings and show that people can hold opposing views despite the commonalities of their experiences. Correspondingly, there were children in the study who demonstrated remarkable resilience despite their constraints. One girl, Sarah, recounted her life story. She told us that there are eight children in her family and that she is the first-born. All the children go to school, apart from one who is not yet in school because he is 'under age'. Her parents are farmers. They grow enough food to eat and then sell the remainder. Sarah told us that the major problem her family experienced was lack of money to facilitate her studies. She says that she dreams of becoming an electrical engineer and works hard at school to achieve this. Sarah's perceptions of her racial disadvantage did not stifle her personal ambition. Such stories show the limits of an interpretation of IGTs that overlooks the challenges and transitions that are occurring on the ground, including among children. However, there is also a tendency to overestimate resilience and such exhibitions of agency and, in the process, to ignore its complexity: people can choose to exercise agency in profoundly negative ways; they may opt not to act at all; moreover, people can exercise agency in one context (such as in public spaces) and refuse to challenge their disadvantage in another (such as in private and intimate spaces). Therefore, public resistance and bravado can coexist with private acceptance and personal shame, which may be revealed, as Goffman (1963) notes, when 'only he [she] and a mirror are about'.

\subsection{Some roots to racial (self) deprecation}

Many children who are growing up in the remote villages that we visited in Uganda are disappointed by what appears to be the permanence of their poverty. Their parents and teachers lack vision of change and transmit messages of futility to their children. These lessons help to undermine children's agency, particularly where lack of progress is associated with their skin colour. However, interviews with the children revealed that the widespread sentiments in these villages are rooted, not only in lessons learnt about the colonial period, demonstrations of 'white wealth' and 'black poverty', lack of exposure to other societies, but also in what is considered to be persistent abuse from 'people like them' as opposed to instances of kindness from 'people not like them'. Children in all parishes reported gross abuse, even from family members, and lack of responsiveness from public officials.

The following synopsis presents a picture of some of the deep reasons for children's distrust of their own race.

Question: Are children in America the same as you?

Some say yes; most say no.

Question: To those who say they are not the same, why do you think this?

We are black they are white.

Our blood is black; theirs is red.

In America or UK parents take good care of their children. They eat good food; we eat leftovers.

Question: What do you think of the sponsors? They are white.

They are rich.

They have more technology than us. 
All of them speak English.

They are not corrupt.

Question: Can you give us some examples of corruption?

Traffic policemen take bribes from taxi drivers.

When one commits a crime, he gives the police money and he is released.

Someone can be given money to construct a school and he eats the money.

An aunt to an orphan can send money to that orphan but the caretakers eat the money.

Question: What sorts of problems do children face at home?

Stepmothers sometimes deny children food and instead pour it away.

Some parents defile us - both boys and girls.

Some parents burn children's hands.

Question: Where do children report cases of abuse?

To local councillors.

To police and prisons.

To the nearest adult.

Question: Who abuses children?

The youth.

Sugar mummies and sugar daddies.

HIV-infected people.

The drunkards.

Those who smoke opium.

Question: What sorts of children are abused? School children.

Babies.

Girls.

Street children.

Question: Whom do you fear the most?

My father, because he is rude.

Our brothers, because they beat us.

My grandfather, because he takes alcohol and, when he does, it causes him to defile me (boy).

These conversations highlight how relationships within communities and families can provoke feelings of fear, distrust and even hatred among children. These relationships have a particularly perverse effect where the limited messages that children receive about and from other races lead many of them to believe the association that they have learnt from their parents; that is, of black skin with evil and white skin with purity. Such is the quality of the indoctrination that children in this study were unable to appreciate the salutary aspects of their own cultures. For example, when questioned, they paid scant regard to the family networks within their villages, which were often key to the survival of the growing numbers of orphans. They did not appreciate how these networks functioned as valuable assets. Similarly, children did not accept examples of black success, preferring to regard the personalities mentioned as people who were 'not fully black'. (Notably, all the persons mentioned resided overseas.) As one official explained, families did not expect, nor were they enthusiastic about, local sponsorship:

\section{Children would be much less excited if the sponsors} were [of national origin].

There's a sponsor in the UK. She sent a letter and the family located her. They told me that they were surprised that there are [nationals of this country] who are donors.

\subsection{Putting race perceptions into context}

It is reasonable to assume that children who live in less remote situations would have different views on race and power, as their contacts with people of different races increase. At the time, the study did not facilitate similar research in the urban centres of Uganda; however, it is possible to conclude, based on experiences in other contexts, that much depends on the quality of the engagement, for where race inequalities are visible - as opposed to purely imagined - perceptions of superiority and inferiority can become even more entrenched. For example, as with other countries in the Caribbean, Jamaica has a history of racial divisions, which is rooted in slavery and colonialism. This legacy persisted into the postcolonial period. As Lewis (1967: 191) describes:

The grim reality of Jamaican life in the mid 1960s was of racial separatism, undeclared yet virulent, that affected every nook and cranny of interpersonal and inter-class relationships, based on a social system characterized by strongly entrenched class-colour correlations.

As I noted above, Jamaica has benefited from some constructive cultural and social changes since those earlier periods. However, paradoxically, while black pride is celebrated in 
many circles, beauty is often still defined in terms of lighter shades and finely textured hair. There are reports of women, men and children who are finding 'alternative' - potentially selfharming - means to lighten their complexions. It is not uncharacteristic to hear parents lament the depth of 'blackness' of their children's complexion or to pronounce that particular children are backward, evil and 'likely to come to no good' because they are 'too black'. Similarly, reggae music - formerly one of the prime avenues of black protest - has, in its modern form, been used to promote the greater desirability of the 'browning' (lighter, mixed race). Inevitably, these messages are being transmitted to children. In a recent round of interviews among 300 students across the social classes in Jamaica, ${ }^{5}$ children reported that some parents and teachers were still inculcating messages about black inferiority. This is because while racial separatism is not as stark as in the $1960 \mathrm{~s}$, colour and class barriers have been difficult to overturn, as deep structural constraints, ingrained beliefs about - and behavioural norms towards - the 'other' sustain divisions and entrench inequalities.

Students explained that these longstanding perceptions may lead to resignation with one's lot, but can also generate antagonisms and conflicts. However, frustrations with perceived race and class inequalities can be channelled in other directions, for while people may endure 'disrespect' from other races, they are much less tolerant of being disrespected by their own and this, as Gilligan (2001) explains in other contexts, is among the reasons for the intra- and intercommunity violence in Jamaica. Notably, Fanon had observed this pattern of response in colonial Algeria. He described it 'as a type of suicidal behaviour', a 'collective auto-destruction':

While the settler or the policeman has the right the live-long day to strike the native, to insult him and to make him crawl to them, you will see the 'native' reaching for his knife at the slightest hostile or aggressive glance cast on him by another native; for the last resort of the native is to defend his personality vis-à-vis a brother ... By throwing himself with all his force into the vendetta, the 'native' tries to persuade himself that colonialism does not exist, that everything is going on as before, that history continues. Here, on the level of communal organizations, we clearly discern the well-known behavior patterns of avoidance. (Fanon 1963: 42)

Fanon acknowledges that this type of conduct 'proves to the settler (whose existence and domination is by them all justified) that these men are not reasonable human beings'. In the same way, the violence among youth and children in Jamaica is rarely rooted in the social inequalities that bred it but is attributed almost exclusively to the perpetrators, who deserve the worse forms of censure.

However, Fanon observed another tendency, where the 'native manages to by-pass the settler'.

A belief in fatality removes all blame from the oppressor; the cause of misfortunes and of poverty is attributed to God; He is fate. In this way, the individual accepts the disintegration ordained by God, bows down before the settler and his lot, and by a kind of interior stabilization acquires a stony calm.

(Fanon 1963: 42)

This acceptance of fate is common in many societies and is also directed at some countries and groups of people who are thought to be cursed by God for sins, including the sin of being born black. Across the Caribbean, for example, it is not uncommon to hear persons argue, forcibly, that Haitians are cursed because 'they are the blackest people within the Caribbean' or to hear Haitians themselves acknowledge that 'nothing good can come to us Haitians; it's sin why we're suffering'. This sin is biblically rooted, some suggest, for wasn't Ham cursed by his father, Noah, and the generations that follow him? And is Ham not the father of the black race? These longstanding perceptions are still an unfortunate part of children's socialisation experiences but with more severe consequences for some children than for others.

In 2005, I conducted research among street children and 'restavecs' - who are among the most marginalised children - in Haiti. I also sought perceptions from elite children, both of the pervasive social divisions in Haiti and of street children and 'restavecs' in particular. Among the elite, predominantly white, children I interviewed, views of 'other' races and classes were not uniform: there was a mixture of benevolence and 
dismissal. However, the street children and 'restavecs' interviewed reported ill treatment from 'others'. One boy told me of his experiences in one racially mixed school. Reginald explained that he was forced to leave home when he was nine years old because his parents did not have the means to provide for him. He said that a benefactor paid for four of them to have piano lessons. All the other children in music school were racially mixed and wealthier. Though his elderly teachers did not treat them unfairly, the children were especially cruel: 'They didn't want to come near us. They say we are back pigs because most of the pigs in Haiti are black'. Reginald decided not to pursue piano lessons. However, 'I would have been good at the keyboards if I had stayed. Then I would have found a band and played for them' (Moncrieffe 2007b).

Reginald's response provides important lessons on the complexity of agency, for while he maintained that he did not care about labels and 'believes that through education, anyone can become great' (his public face), he also gave up on music lessons. Moreover, he confessed that while he wished to work to change his circumstances in positive ways (his strategic preference), he also exercised his agency in negative ways, since he was forced to do so in order to survive on the streets (his tactical choice).

\section{Cultivating agency?}

The subjective and relational dimensions of children's wellbeing are critical to who they are and to their capacities to exercise agency, to transform their circumstances in constructive ways (see, for example, Montalvo 2004).

Individuals are not compartmentalised, such that the material proceeds without reference to the social; similarly, people's social and cultural existences are linked to the material. Bifurcated development approaches can provide weak solutions and even exacerbate certain forms of inequalities. For example, sponsorship programmes ought to be sensitive to the adverse relationships of power that can attend 'gifts'. As Mauss (2001) explained, all gift relationships bring their obligations and expectations. Both the giver and the recipient expect some reciprocity, and the less able one is to reciprocate, the more one feels inferior. There are huge implications when this inferiority - compounded in certain circumstances by race - is cultivated from childhood and transmitted across generations.
On the contrary, a sponsorship programme that is sensitive to race would seek to cultivate the cross- and intra-group relations, such that young children would have better knowledge of other children's realities, including the commonalities of experiences of poverty and inequality. Such a sponsorship programme might ensure that there are visible positive representations of children's race, recognising that forms of agency spring from the power relations that are internalised. Challenging the patterns of meanings that sustain racial inequalities is crucial for ensuring that children have the best means, mechanisms and opportunities to exercise positive agency, as it is conventionally conceptualised; that is, to transform themselves and their circumstances.

How can development actors build the conditions so that all children have better prospects to make strategic rather than tactical choices?

As White (2002) suggests, challenging cultures of meaning requires attention to perceptions and relations within development agencies. The case examples above reinforce the importance of 'systematic and rigorous self critical practice' (Swartz 1997), particularly of how ingrained perceptions of race influence the quality of interventions. The stories also highlight some specific and urgent policy responses. These include development policies that address the structural constraints that children experience, such as deep levels of poverty, inadequate access to quality education; and ineffective legal systems that fail to protect their rights in visible and convincing ways. They show the importance of improved parenting, such that parents are able and equipped to transfer human capital to secure the futures of their children. However, policies must, necessarily, go beyond these to address the relational and the subjective; for example, through educating in ways that prompt meaningful transformations by tackling inequalities at their roots. Recognising the meanings of race, the reasons for these meanings and the ways in which these meanings contribute to problems such as conflicts and violence within and across communities is critical for any development agenda that aims to improve the wellbeing of all, not just some, of our children.

Thus the native discovers that his life, his breath, his beating heart are the same as those of the settler. He finds that the settler's 
skin is not of any more value than a native' skin; and it must be said that this discovery

\section{Notes}

1 See Introduction to this IDS Bulletin for a discussion of 'intersectionalities'.

2 'Restavecs' literally means 'stay with us' and refers to children who are sent, largely from rural areas, to live with family and strangers, who should house, clothe and send them to school in return for light household work. This arrangement works in some cases. However, in many, these children are exploited, such that 'restavecs' are often informally classified as child slaves.

3 Across the disciplines, there is a wide range of literature on childhood socialisation processes: for example, psychologists focus on the interactions of biology, brain and the

\section{References}

Babb, K.C. (2002) 'Overcoming Race Division to Maximize Our Agency: The Caribbean Women's Movement', report for the World Conference Against Racism, August 2002, unpublished

Barnes, B. (2000) Understanding Agency: Social Theory and Responsible Action, London: Sage

Bourdieu, P. (1980) The Logic of Practice, Stanford: Stanford University Press

Chabal, P. and Daloz, J.P. (1988) Culture Troubles: Politics and the Interpretation of Meaning, London: Hurst and Company

De la Fuente, A. (2001) 'The Resurgence of Racism in Cuba', NACLA Report on the Americas 34.6, May-June

Dill, K. (2001) 'The Role of the Human Rights Commission: The Bermuda Experience', paper for the Cayman Islands Human Rights Conference, 10-14 September, unpublished

Fanon, F. (1963) The Wretched of the Earth, New York: Grove Press

Foucault, M. (1980) (C. Gordeon, ed.) Power/Knowledge: Selected Interviews and Other Writings, 1972-77, Brighton: Harvester

Foucault, M. (1972) The Archeology of Knowledge, (A.M. Sheridan-Smith, trans.) London: Tavistock Geertz, C. (1973) The Interpretation of Cultures: Selected Essays, New York: Basic Books

Gilligan, J. (2001) Preventing Violence: Prospects for Tomorrow, New York: Thames \& Hudson shakes the world in a very necessary manner. (Fanon 1963: 35)

environment; social learning theorists emphasise how behaviours are learnt - such as through reward and punishment and imitation - throughout childhood; social psychologists emphasise how social surroundings help to shape children's psychological development.

4 Here, it was important to note the prejudices and stratifications that exist within groups, even those who consider themselves commonly disadvantaged. This reinforces the importance of studying intersectionalities, as they expose the non-uniformity of poverty and inequalities.

5 These interviews were carried out from September 2006 to May 2007.

Goffman, E. (1963) Stigma: Notes on the Management of Spoiled Identity, Englewood Cliffs: PrenticeHall; reprinted (1968) Harmondsworth: Penguin Hayward, C.R. (2000) De-Facing Power, Cambridge: Cambridge University Press

Jenkins, R. (2004) Social Identity, London: Routledge

Lewis, G. (1967) The Growth of the Modern West Indies, London: MacGibbon and Kee

Mauss, M. (2001) The Gift: The Form and Reason for Exchange in Archaic Societies, London: Routledge

McKnight, F. (1996) 'Ethnicity and Social Structure in Contemporary Cuba', in G. Oostinde (ed.), Ethnicity in the Caribbean, London: Macmillan

Moncrieffe, J. (2007a) 'Labelling, Power and Accountability: How and Why Our Categories Matter', in J. Moncrieffe and R. Eyben (eds), The Power of Labelling: How People are Categorized and Why it Matters, London: Earthscan

Moncrieffe, J. (2007b) 'When Labels Stigmatise: Encounters with Street Children and Restavecs in Haiti', in J. Moncrieffe and R. Eyben (eds.), The Power of Labelling: How People are Categorized and Why it Matters, London: Earthscan

Moncrieffe, J. (2004) Ethnic Diversity and State Response in the Caribbean, Background Paper for the Human Development Report 2004, http://origin-hdr.undp.org/en/reports/global/ hdr2004/papers/hdr2004_joy_moncrieffe.pdf (accessed 10 November 2008) 
Montalvo, F. (2004) 'Surviving Race: Skin Color and the Socialization and Acculturation of Latinas', Journal of Ethnic \& Cultural Diversity in Social Work 13.3: 25-43

Mudimbe, V.Y. (1988) The Invention of Africa: Gnosis, Philosophy and the Order of Knowledge, Bloomington: Indiana University Press

Ross, M.H. (1997) 'Culture and Identity in Comparative Political Analysis', in M. Lichbach and A. Zuckerman (eds), Comparative Politics: Rationality, Culture and Structure, Cambridge: Cambridge University Press

Scott, J. (1985) Weapons of the Weak: Everyday Forms of Peasant Resistance, London: Yale University Press
Swartz, D. (1997) Culture and Power. The Sociology of Pierre Bourdieu, Chicago: University of Chicago Press

UNFPA (2008), Reaching Common Ground: Culture, Gender and Human Rights, State of World Population Report, New York: United Nations Population Fund

Wacquant, L. (2005) 'Habitus', in J. Becket and M. Zafiovski (eds), International Encyclopedia of Economic Sociology, London: Routledge

White, S. (2002) 'Thinking Race, Thinking Development', Third World Quarterly 23.3: 407-19

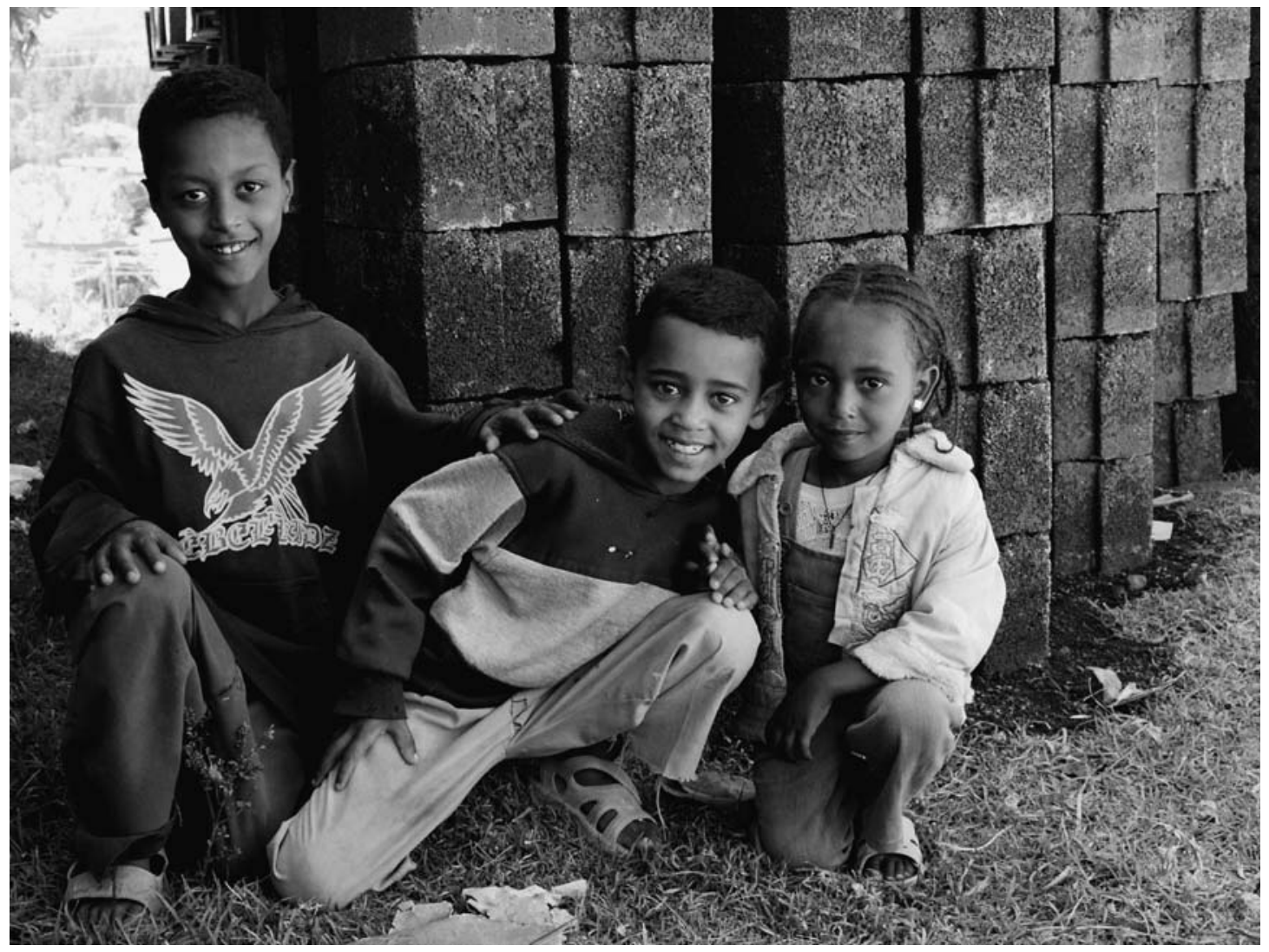

Children playing in the slums in Ethiopia: resilience and vulnerability. Photo: Martin Moncrieffe 